\title{
Bronchopulmonary Dysplasia: A Historical Perspective
}

\author{
Julian Allen ${ }^{1}$ and Howard Panitch ${ }^{1}$ \\ ${ }^{1}$ The Children's Hospital of Philadelphia
}

December 12, 2020

\begin{abstract}
Bronchopulmonary dysplasia (BPD) was first described by Northway et al in 1967. This article describes the evolution of our understanding of the pathophysiology of BPD and the approaches to treatments of this illness developed over the past fifty years. These interventions had their roots in the understanding of the principles of the surface tension present at air- liquid interfaces, which were developed over 150 years before BPD's initial description. Improving outcomes in neonatal care have led to greater survival of preterm and very preterm infants, and to an evolution of the pathogenesis and pathology of BPD, from an illness caused primarily by barotrauma and oxygen toxicity to one of interruption of lung development. While the incidence of BPD has remained about the same in recent decades, this is because survival of infants born at lower gestational ages is increasing. Understanding of molecular, genetic and physiologic mechanisms has led to newer treatments that have mitigated some of the harmful effects of prolonged mechanical ventilation. Recognition of BPD as a chronic multi-system disease has resulted in further improvements in care after discharge from neonatal intensive care. Since many of the origins of chronic obstructive lung disease in adults are based in childhood respiratory illnesses, improving outcomes of BPD in infancy and childhood will undoubtedly lead to improved respiratory outcomes in the adults that these children will become.
\end{abstract}

\section{Bronchopulmonary Dysplasia-A HISTORICAL PERSPECTIVE}

Pediatric Pulmonology 12.09.20

Julian Allen and Howard Panitch

Bronchopulmonary dysplasia (BPD), or chronic lung disease of infancy, was first described by Northway et al in 1967 in a now classic article (1). The authors presented radiographic and pathologic findings in a series of 32 newborn preterm infants who developed hyaline membrane disease, required supplemental oxygen and/or mechanical ventilation, and who subsequently developed abnormal chest radiographs and chronic supplemental oxygen requirement. Philip reviewed the relative contributions of oxygen, positive pressure, and lung injury to the development of BPD (2). However, much of our current understanding of the pathophysiology of BPD actually antedates the first 1967 description.

Pre- 1960. The first relevant publication to the pathophysiology of BPD dates back to 1805 when LaPlace (quantitatively) and Young (qualitatively) described the relationship between radius, surface tension and pressure in spheres with an air- liquid interface (3). The simplified version of their equation,

$\mathrm{P}=2 \mathrm{~T} / \mathrm{r}$ (or $4 \mathrm{~T} / \mathrm{r}$ if there are inside and outside interfaces)

explains how a smaller radius of curvature $(\mathrm{r})$ generates a higher pressure $(\mathrm{P})$ given a constant surface tension (T). It also implies that it will be difficult for connected spheres of different radii to co-exist if their surface tensions are equal; the smaller spheres, having higher pressures, will tend to empty into the larger spheres. These phenomena of surface tension at air-liquid interfaces were beautifully demonstrated in an elegant series of children's lectures delivered by C.V. Boys and published as "Soap-bubbles and the forces which mould them. Being a course of three lectures delivered in the theatre of the London Institution on the afternoons of Dec. 30, 1889, Jan. 1 and 3, 1890, before a juvenile audience (4)." He demonstrated the 
requirement of an air-liquid interface for individual hairs of a paintbrush to stick together by surface tension, whereas a submerged brush had no such interface and therefore the hairs were not attracted to one another (Figure 1). He furthermore demonstrated that soap bubbles with small radii empty into those with large radii (Figure 2). The inherent instability of a lung composed of alveoli of different sizes led Avery and Mead to postulate the existence of a surface tension-lowering agent in the lung, the absence of which in infants with hyaline membrane disease reduced lung compliance and could lead to the respiratory distress syndrome (Figure 3) (5). Their work also showed the reduction of surface tension at smaller surface areas due to the increasing concentration of surfactant as it was "compressed" as surface area decreased. This concept, when applied to the surface of spheres, in turn allows for the coexistence of alveoli of different radii; if the T/r ratio remains relatively constant as the radius decreases, this tends to equalize the pressure between alveoli of different sizes. There were also therapies that antedated the description of BPD that played a role in the increased survival of premature infants. In 1958, Silverman described the importance of the thermal environment in improving preterm survival (6). In 1963, Usher demonstrated the importance of nutrition for babies with RDS with the use of glucose and bicarbonate intravenous infusions to improve survival (7). The 1960s. Prior to the introduction of mechanical ventilation, the mortality of infants $<28$ weeks' gestation or extremely low birthweight (ELBW: $<1,000 \mathrm{~g}$ ) exceeded $90 \%$. The most famous example of mortality related to prematurity, and one which raised the level of public awareness of this problem, was the death of the infant son of President and Jacqueline Kennedy that occurred in 1963 (Figure 4). The infant was $34 \frac{1}{2}$ weeks gestation and weighed $2.1 \mathrm{~kg}$ (4lb 10oz), large by today's standards. At the time, however, survival from hyaline membrane disease was rare, even at a gestational age of 35 weeks. The death of baby Patrick Kennedy was a driving force for the development of research efforts aimed at reducing mortality related to preterm birth. Before Northway's report, Wilson and Mikity described a syndrome of oxygen dependence and chest radiographic abnormalities in preterm infants (8); however, these infants had not received mechanical ventilation, and had received little or no supplemental oxygen at birth. Northway's series was the first to describe lung disease associated with mechanical ventilation and supplemental oxygen administration; those preterm infants had received amounts of supplemental oxygen as high as $80 \%$, but for as little as 150 hours (1). Hawker described a similar syndrome in infants who had been treated with up to $60 \%$ oxygen for as little as 120 hours (9). Northway's original paper went on to describe 4 stages of disease progression with associated radiographic changes. Stage 1 reflected classic hyaline membrane disease with ground glass pattern and air bronchograms on chest radiographs (Figure 5). Stage 2 was a period of regeneration. Stage 3 described a period of transition with developing hyperinflation and interstitial thickening indicative of airway disease and parenchymal fibrosis (Figure 6), and stage 4 described established chronic disease. At about this time in the late 1960s, several investigators described the pathology of oxygen toxicity in humans and animal models, as well as subsequent mucociliary dysfunction (10-13), and it was proposed that the changes of BPD were at least in part due to oxygen toxicity $(1,14)$.The 1970s. The next decade saw a large increase not only in our understanding of causal factors in the development of BPD, but also the introduction of significant new therapies. In 1972, Liggins et al reported on the use of prenatal maternal betamethasone to reduce the severity and incidence of neonatal RDS in infants born prematurely (15). However, the treatment was not adopted as a widespread practice until the 1990s $(16,17)$. At about this time, the understanding of the pathogenesis of BPD was being refined with the concept of "oxygen plus pressure plus time" (18). Specific ventilators were being introduced for use in infants. An NIH consensus conference in 1978 refined the nosology of chronic lung disease of infancy, distinguishing pathological definitions ("bronchopulmonary dysplasia") from clinical definitions (e.g., supplemental oxygen requirement at 28 days of postnatal life vs. 36 weeks postconceptional age) (19). The understanding of the role of pressure in the development of lung injury led to novel ways to support infants with RDS with the least amount of barotrauma. The most successful of these was the introduction of continuous positive airway pressure ("bubble CPAP") by an anesthesiologist at Columbia Presbyterian's Babies Hospital $(20,21)$. This ingenious set- up provided CPAP by submerging the distal end of an oxygen catheter in a container of water to the depth that reflected the amount of CPAP desired, often $5 \mathrm{~cm} \mathrm{H}_{2} 0$. (Figure 7). The processes of weaning from mechanical ventilation were also described during this time. Morray et al reported that infants requiring prolonged mechanical ventilation reached a "halfway point" at which time a reduction in their $\mathrm{pCO}_{2}$ heralded an ability to progress with gradual mechanical 
ventilation withdrawal, characterized by a reduction in spontaneous respiratory rates, tolerance of a reduction in mandatory ventilator rates, and a period of sustained improved weight gain (22). It was also in the 1970s that clinicians reported the first experiences sending infants to home while being treated with supplemental oxygen. Pinney and Cotton described home oxygen delivered by nasal cannula (23). The early monitoring of oxygen saturation was accomplished with transcutaneous $\mathrm{PO}_{2}$ monitoring (24). It was not until the next decade that pulse oximetry was introduced.The 1980s. This decade saw increasing numbers of studies of oxidative lung damage mechanisms, including the amplifying of hypoxia and reoxygenation in the lungs (25) and in the brain (26). Those observations led to several clinical trials of the use of putative antioxidants, e.g., superoxide dismutase, vitamin A and vitamin D $(27,28)$. In addition, investigators began to recognize the role of maternal chorioamnionitis in predisposing towards the development of BPD (29). Furthermore, controlled clinical trials involving the use of corticosteroids to enable infants with chronic lung disease to be weaned from mechanical ventilation (30-32) extended observations that began in the 1970s (33). Such investigations were based on recognition of the anti-inflammatory properties of those drugs. Simultaneously, however, others showed that in animals that undergo postnatal alveolarization, the systemic exposure of the lung to glucocorticoids hastens maturation of the capillary membrane, resulting in an inhibition of alveolarization (34). Another important advance was the recognition that pulmonary edema played a role in the pathogenesis of BPD (35), and that its control with fluid management, diuretics, and correction of a patent ductus arteriosus to prevent fluid overload could be helpful in improving the lung mechanics of infants with $\operatorname{BPD}(36,37)$. Other studies that used lung mechanics measurements as primary outcomes showed that bronchodilators like theophylline were effective (38). Further advances during this decade included recognition of the crucial role that nutrition plays in supporting the overall growth of the infant and the growth of lung parenchyma and airway size (39). This decade also saw the first reports of the use of exogenous surfactant in preventing severe RDS (40). To facilitate hospital discharge, home supplemental oxygen came into more widespread use (41), made more practical with monitoring by home pulse oximetry. Twenty years after BPD was first described, Avery and coworkers published a report that provided crucial understanding of the how clinical practices, including the use of positive pressure-sparing strategies, could reduce the incidence of BPD (20). The authors reported a significant difference in incidence of BPD among the 8 tertiary care NICUs studied even when birth weight, race, and sex were taken into consideration through a multivariate logistic regression analysis. The Center that had one of the best outcomes for low birth weight infants and the lowest incidence of chronic lung disease employed the use of bubble CPAP (Figure 7) (21) as well as the identification of a single provider from the Anesthesiology Department who took over the infants' respiratory care. Other factors that improved outcomes in that study included avoidance of pharmacologic paralysis, more permissive $\mathrm{pH}$ targets, and differences in fluid management. Gradually, the decade also saw more acceptance of lung protective ventilation strategies that minimized pressure swings and barotrauma, with avoidance of intubation when possible, volume targeted ventilation, permissive hypercapnia, and high frequency ventilation (42). The contribution of central airway abnormalities like tracheobronchomalacia to chronic or episodic respiratory distress was first recognized during this decade as well (43), as was the safety and efficacy of diagnosing central airway problems with flexible bronchoscopy (44). The 1990s. The decade saw further documentation of the role of chorioamnionitis in contributing to the development of chronic lung disease, and the introduction of artificial surfactants (Exosurf (C) and Survanta(C). These improvements in care fundamentally altered the pathology of BPD. This new pathology was characterized less by parenchymal fibrosis and airway damage and more by abnormalities in lung development, leading primarily to alveolar simplification (45). During this decade, the outcome for most preterm infants was altered substantially. Not only did survival improve for each gestational age, but the severity of residual lung damage also decreased (46). Another advance that allowed for reduction of the $\mathrm{FiO}_{2}$ required to achieve minimal oxygen saturation targets came with the introduction of inhaled nitric oxide (iNO) into clinical practice (47). This agent improved ventilation/perfusion mismatch in the lungs, enhancing perfusion by acting as a vasodilator only to those areas of the lung that were ventilating well enough to allow entry of the NO. This was an era where there was also much study of the optimal oxyhemoglobin targets for end organ oxygenation while minimizing oxidative damage to the lungs and retinae to prevent retinopathy of prematurity. Kotecha summarized these studies in 2002 (48), and recommended a target range of at 
least $94-96 \%$ and avoidance of oxygen saturations $<92 \%$. He also acknowledged that the saturation target range for very preterm infants at risk of developing ROP was more controversial, due to a probably narrower therapeutic range $(49,50)$. Finally starting in the 1980s, and continuing into the 2000s, the use of infant lung function testing, including tidal breathing mechanics, respiratory inductive plethysmography, the thoracic compression technique and the raised volume thoracic compression technique, gas mixing evaluations such as the nitrogen washout technique and oscillometry to characterize the physiologic derangements in BPD came into more widespread use $(51,52)$. Improvements in lung mechanics with the application of CPAP with or without custom tracheostomy tubes $(53,54)$ or pharmacologic interventions like cholinergic agents $(55)$ were described in infants with tracheo-bronchomalacia. This is also the time that the concept of non-invasive ventilation as a modality to reduce BPD was introduced, with ongoing studies into the next decade (56). Although home mechanical ventilation of infants with severe BPD began in the late 1970s, guidelines for the care of infants and children with chronic respiratory failure secondary to BPD, and the equipment needs for those children were not published until the 1990s when such care became more standardized $(57,58)$.

The 2000s. An American Thoracic Society Statement on the care of the child with chronic lung disease was published that emphasized the appreciation of BPD as a multisystem disease (59). This concept was summarized in a figure emphasizing the interaction between the various organ systems affected by BPD (Figure 8).

Investigators had long recognized alterations in the pulmonary vasculature that accompanied parenchymal lung disease in infants with BPD, but they began to describe the relationship between severe BPD and pulmonary hypertension, and how the presence of pulmonary hypertension increased late mortality of BPD children (60). In addition, small series reported the successful treatment of infants with BPD and pulmonary hypertension using sildenafil (61).

In 2006, a clinical trial of caffeine therapy for apnea of prematurity, given to infants of gestational age as young as 27 weeks who were just under $1000 \mathrm{gm}$, demonstrated a reduction in the incidence of BPD $(62,63)$. The decade also ushered in studies exploring the genetic underpinnings of BPD, including genetic variants of surfactant proteins $(64,65)$ and numerous other genomic and proteomic markers $(66,67)$.

The 2010s. Additional studies of BPD pathogenesis have taken place in the past decade, expanding our knowledge of mechanisms of lung injury in animal models, including the roles of chorioamnionitis, postnatal inflammation, oxygen toxicity and barotrauma, Ureaplasma urealyticum infections and genetics (68-71). Further trials of treatment with postnatal systemic steroids emphasized short term, low dose protocols balancing the aim of minimizing time on mechanical ventilation with adverse neurodevelopmental consequences (72-74). Greater appreciation of the role of the altered pulmonary vasculature and pulmonary hypertension in severe BPD led to clinical trials of iNO (75) and other therapies (76). Investigators also proposed novel therapies with insulin-like growth factor 1 (IGF-1) and mesenchymal stem cells (71). As the number of infants with severe BPD who required prolonged mechanical ventilation (Type 2 severe BPD) increased (77), experts promoted modifications of ventilator strategies, changing from the low tidal volume lung-protective strategies used to prevent the development of BPD to strategies that allow for more even distribution of ventilation in the severely affected BPD lung, including higher tidal volumes, lower mandatory inspiratory rates and longer inspiratory and expiratory times (78). Recognition of the presence of dynamic hyperinflation and the development of intrinsic PEEP in infants with the most severe lung disease led investigators to use higher levels of PEEP to improve patient-ventilator synchrony (79). One novel approach now under investigation comes full circle to the surface tension problem described by C.V. Boys in the 1890s, as outlined above, with the investigation of "liquid" ventilation as a way to abolish the air/liquid interface altogether (80).

Evolving definitions of BPD With the improved outcome for earlier gestational age infants came a recognition that the pathology of BPD had changed as well, from parenchymal fibrosis and airway damage to arrest of alveolar development (71). Part of the problem of interpreting studies of BPD spanning several decades is that the definitions of BPD have changed since it was first described by Northway in 1967 (81). Initial definitions combined the need for supplemental oxygen at 30 days of life with radiographic 
changes (82), while subsequent definitions refined clinical criteria but maintained stereotypical radiographic findings as a criterion (83). In 1988, a simplified definition of BPD was proposed, based on the need for supplemental oxygen use at 36 weeks postmenstrual age in preterm infants born $<1500 \mathrm{~g}$, a definition that remains in common use (84). The rationale for this change from a simple supplemental oxygen requirement at 28 days is that as infants born at earlier and earlier gestational ages were surviving, a supplemental oxygen requirement at 28 days in a 36 week gestation infant likely meant more significant disease than a supplemental oxygen requirement at 28 days in a 28 week gestation infant. An NIH workshop in 2000 further refined the definitions with differing criteria for infants greater or less than 32 weeks gestational age, and added categories of mild, moderate, and severe BPD depending on supplemental O2 and positive pressure requirements: mild (weaned to room air), moderate ( $<30 \%$ supplemental oxygen requirement) and severe ( $>30 \%$ supplemental oxygen requirement or need for positive pressure). Further refinement of the severe definition into Type 1 (supplemental oxygen dependence) and Type 2 (ventilator dependence) has led to patient groupings that allow different treatment strategies to be compared within the various severity groups (85). Newer strategies for respiratory support, like use of heated, humidified high-flow therapy challenge current definitions of BPD; this problem will persist as long as definitions of BPD rely upon therapies used.

The net result of all the improvements in BPD care have led to a somewhat paradoxical stability in its incidence. A Neonatal Research Network study showed no change and even a slight increase in incidence of BPD over last several decades (86), likely resulting from a balance between increased survival of infants of very low gestational age and birthweight, and a reduced incidence of BPD at any given gestational age. However, despite improved neonatal care and survival, BPD prevalence remains high at $35 \%-40 \%$ among extremely low gestational age neonates $(<28$ weeks GA), and thus BPD continues to occur among 10 to $50 \%$ of all premature infants internationally $(71)$.

The future. Respiratory clinicians increasingly appreciate that the roots of adult chronic obstructive lung disease arise in the pediatric pulmonary experience (87). Infants with recurrent wheeze are at increased risk of developing asthma in childhood, and children who wheeze throughout childhood are at increased risk of developing COPD and the asthma/COPD overlap syndrome in adulthood (88). BPD is undoubtedly a risk factor for these adult conditions as well (89). Thus, the history of BPD is still very much still being written. As the care for infants and children with BPD continues to improve, so will the respiratory health of the adults they will become.

\section{FIGURE LEGENDS}

Figure 1. Demonstration of surface tension by C.V. Boys (4). Right, when a brush is wetted and held in the air, the air- liquid interfaces causes the bristles of the brush to attract one another and stick together. However, when a brush is dry and held in the air, the lack of an air liquid interface allows the bristles to remain separate (Left). Similarly, when a brush is completely submerged in water, the lack of an air liquid interface allows the bristles to remain separate (Center).

Figure 2. Demonstration of the Law of LaPlace by C.V. Boys (4). Since the LaPlace equation states $\mathrm{P}=$ $4 \mathrm{~T} / \mathrm{r}$, bubbles of smaller radii have higher pressure and air will flow from the smaller bubble to the larger bubble.

Figure 3. Demonstration of the role of surfactant in reducing surface tension in lung extracts by Avery and Mead (5). Lung extracts from a 2990g infant (A) and an adult (B) have lower surface tension than extracts from a $480 \mathrm{~g}$ infant $(\mathrm{C})$ and a $3300 \mathrm{~g}$ infant with hyaline membrane disease. The positive slope of the surface tension/area curve indicates the essential role of surfactant in lowering surface tension to a greater extent when the area of the surface (and therefore the radius of the alveolus) is compressed due to its higher concentration. Unlike other lipid "soaps," surfactant remains on the surface and does not go into the aqueous phase as the surface is compressed.

Figure 4. Front page of Boston Globe, August 8, 1963. Report of the respiratory illness of the son of President and Mrs. Kennedy, born at $34 \frac{1}{2}$ weeks gestation, due to neonatal respiratory distress syndrome (hyaline membrane disease) 
Figure 5. Stage 1 BPD (Hyaline Membrane disease). Radiographic appearance of ground glass infiltrates and air bronchograms, and pathology showing sloughed hyaline membranes in alveoli and a small bronchus (From (1)).

Figure 6. Stage 3 BPD. Radiographic appearance of muti-loculated cysts and pathology showing bronchiolar metaplasia and peribronchiolar smooth muscle hyperplasia (From (1))

Figure 7. Schematic of an early CPAP system, "bubble CPAP." Constant positive airway pressure is adjusted by increasing flow through the nasal cannula until bubbles appear in the container with the distal end of the cannula. The degree of CPAP is determined by the depth of the cannula under the water. (From (21)).

Figure 8. A graphic representation of the multi-system nature of BPD, and how pathology of various organ systems affect one another. For example, the arrow from Pulmonary to Nutrition indicates that the increased work of breathing due to abnormal lung mechanics steals calories required for growth, whereas the arrow from Nutrition to Pulmonary indicates that under-nutrition affects respiratory muscles, pulmonary parenchymal and airway growth, and ultimately repair of damaged lung. (59)

\section{References}

1. Northway WH, Jr., Rosan RC, Porter DY. Pulmonary disease following respirator therapy of hyalinemembrane disease. Bronchopulmonary dysplasia. N Engl J Med. 1967;276(7):357-68.

2. Philip AG. Chronic lung disease of prematurity: a short history. Semin Fetal Neonatal Med. 2009;14(6):3338.

3. Young T. An essay on the cohesion of fluids. Philosophical Transactions of the Royal Society of London. 1805;95:65-87.

4. Boys C. Soap-bubbles and the forces which mould them. Being a course of three lectures delivered in the theatre of the London Institution on the afternoons of Dec. 30, 1889, Jan. 1 and 3, 1890, before a juvenile audience. In: Knowledge SfPC, editor. London, New York: E. \& J. B. Young; 1890. p. 09-50.

5. Avery ME, Mead J. Surface properties in relation to atelectasis and hyaline membrane disease. AMA J Dis Child. 1959;97(5, Part 1):517-23.

6. Silverman WA, Fertig JW, Berger AP. The influence of the thermal environment upon the survival of newly born premature infants. Pediatrics. 1958;22(5):876-86.

7. Usher R. Reduction of Mortality from Respiratory Distress Syndrome of Prematurity with Early Administration of Intravenous Glucose and Sodium Bicarbonate. Pediatrics. 1963;32:966-75.

8. Wilson MG, Mikity VG. A new form of respiratory disease in premature infants. AMA J Dis Child. 1960;99:489-99.

9. Hawker JM, Reynolds EO, Taghizadeh A. Pulmonary surface tension and pathological changes in infants dying after respirator treatment for severe hyaline membrane disease. Lancet. 1967;2(7506):75-7.

10. DeLemos R, Wolfsdorf J, Nachman R, Block AJ, Leiby G, Wilkinson HA, et al. Lung injury from oxygen in lambs: the role of artificial ventilation. Anesthesiology. 1969;30(6):609-18.

11. Giammona ST, Kerner D, Bondurant S. Effect of oxygen breathing at atmospheric pressure on pulmonary surfactant. J Appl Physiol. 1965;20(5):855-8.

12. Kaplan HP, Robinson FR, Kapanci Y, Weibel ER. Pathogenesis and reversibility of the pulmonary lesions of oxygen toxicity in monkeys. I. Clinical and light microscopic studies. Lab Invest. 1969;20(1):94-100.

13. Nash G, Blennerhassett JB, Pontoppidan H. Pulmonary lesions associated with oxygen therapy and artifical ventilation. N Engl J Med. 1967;276(7):368-74. 
14. Coalson JJ, Winter VT, Siler-Khodr T, Yoder BA. Neonatal chronic lung disease in extremely immature baboons. Am J Respir Crit Care Med. 1999;160(4):1333-46.

15. Liggins GC, Howie RN. A controlled trial of antepartum glucocorticoid treatment for prevention of the respiratory distress syndrome in premature infants. Pediatrics. 1972;50(4):515-25.

16. McCarthy M. US recommendations for antenatal corticosteroids. Lancet. 1994;343(8899):726.

17. Van Marter LJ, Leviton A, Kuban KC, Pagano M, Allred EN. Maternal glucocorticoid therapy and reduced risk of bronchopulmonary dysplasia. Pediatrics. 1990;86(3):331-6.

18. Philip AG. Oxygen plus pressure plus time: the etiology of bronchopulmonary dysplasia. Pediatrics. 1975;55(1):44-50.

19. Workshop on bronchopulmonary dysplasia. Sponsored by the Division of Lung Diseases. National Heart, Lung, and Blood Institute, National Institutes of Health. J Pediatr. 1979;95(5 Pt 2):1-9, 815-920.

20. Avery ME, Tooley WH, Keller JB, Hurd SS, Bryan MH, Cotton RB, et al. Is chronic lung disease in low birth weight infants preventable? A survey of eight centers. Pediatrics. 1987;79(1):26-30.

21. Morley CJ, Lau R, De Paoli A, Davis PG. Nasal continuous positive airway pressure: does bubbling improve gas exchange? Arch Dis Child Fetal Neonatal Ed. 2005;90(4):F343-4.

22. Morray JP, Fox WW, Kettrick RG, Downes JJ. Clinical correlates of successful weaning from mechanical ventilation in severe bronchopulmonary dysplasia. Crit Care Med. 1981;9(12):815-8.

23. Pinney MA, Cotton EK. Home management of bronchopulmonary dysplasia. Pediatrics. 1976;58(6):856-9.

24. Philip AG, Peabody JL, Lucey JF. Transcutaneous Po2 monitoring in the home management of bronchopulmonary dysplasia. Pediatrics. 1978;61(4):655-7.

25. Saugstad OD. Oxygen radicals and pulmonary damage. Pediatr Pulmonol. 1985;1(3):167-75.

26. Mishra OP, Delivoria-Papadopoulos M. Lipid peroxidation in developing fetal guinea pig brain during normoxia and hypoxia. Brain Res Dev Brain Res. 1989;45(1):129-35.

27. Saldanha RL, Cepeda EE, Poland RL. The effect of vitamin E prophylaxis on the incidence and severity of bronchopulmonary dysplasia. J Pediatr. 1982;101(1):89-93.

28. Shenai JP, Kennedy KA, Chytil F, Stahlman MT. Clinical trial of vitamin A supplementation in infants susceptible to bronchopulmonary dysplasia. J Pediatr. 1987;111(2):269-77.

29. Fujimura M, Takeuchi T, Kitajima H, Nakayama M. Chorioamnionitis and serum IgM in Wilson-Mikity syndrome. Arch Dis Child. 1989;64(10 Spec No):1379-83.

30. Avery GB, Fletcher AB, Kaplan M, Brudno DS. Controlled trial of dexamethasone in respiratordependent infants with bronchopulmonary dysplasia. Pediatrics. 1985;75(1):106-11.

31. Cummings JJ, D'Eugenio DB, Gross SJ. A controlled trial of dexamethasone in preterm infants at high risk for bronchopulmonary dysplasia. N Engl J Med. 1989;320(23):1505-10.

32. Mammel MC, Green TP, Johnson DE, Thompson TR. Controlled trial of dexamethasone therapy in infants with bronchopulmonary dysplasia. Lancet. 1983;1(8338):1356-8.

33. Philip AG. Treatment of bronchopulmonary dysplasia with corticosteroids. Clin Res. 1974;22:242 (Abstract).

34. Massaro D, Teich N, Maxwell S, Massaro GD, Whitney P. Postnatal development of alveoli. Regulation and evidence for a critical period in rats. J Clin Invest. 1985;76(4):1297-305.

35. Brown ER, Stark A, Sosenko I, Lawson EE, Avery ME. Bronchopulmonary dysplasia: possible relationship to pulmonary edema. J Pediatr. 1978;92(6):982-4. 
36. Engelhardt B, Blalock WA, DonLevy S, Rush M, Hazinski TA. Effect of spironolactonehydrochlorothiazide on lung function in infants with chronic bronchopulmonary dysplasia. J Pediatr. 1989;114(4 Pt 1):619-24.

37. Kao LC, Warburton D, Sargent CW, Platzker AC, Keens TG. Furosemide acutely decreases airways resistance in chronic bronchopulmonary dysplasia. J Pediatr. 1983;103(4):624-9.

38. Kao LC, Durand DJ, Phillips BL, Nickerson BG. Oral theophylline and diuretics improve pulmonary mechanics in infants with bronchopulmonary dysplasia. J Pediatr. 1987;111(3):439-44.

39. Frank L, Sosenko IR. Undernutrition as a major contributing factor in the pathogenesis of bronchopulmonary dysplasia. Am Rev Respir Dis. 1988;138(3):725-9.

40. Fujiwara T, Maeta H, Chida S, Morita T, Watabe Y, Abe T. Artificial surfactant therapy in hyalinemembrane disease. Lancet. 1980;1(8159):55-9.

41. Hudak BB, Allen MC, Hudak ML, Loughlin GM. Home oxygen therapy for chronic lung disease in extremely low-birth-weight infants. Am J Dis Child. 1989;143(3):357-60.

42. High-frequency oscillatory ventilation compared with conventional mechanical ventilation in the treatment of respiratory failure in preterm infants. The HIFI Study Group. N Engl J Med. 1989;320(2):88-93.

43. Sotomayor JL, Godinez RI, Borden S, Wilmott RW. Large-airway collapse due to acquired tracheobronchomalacia in infancy. Am J Dis Child. 1986;140(4):367-71.

44. Cohn RC, Kercsmar C, Dearborn D. Safety and efficacy of flexible endoscopy in children with bronchopulmonary dysplasia. Am J Dis Child. 1988;142(11):1225-8.

45. Jobe AJ. The new BPD: an arrest of lung development. Pediatr Res. 1999;46(6):641-3.

46. Horbar JD, Badger GJ, Carpenter JH, Fanaroff AA, Kilpatrick S, LaCorte M, et al. Trends in mortality and morbidity for very low birth weight infants, 1991-1999. Pediatrics. 2002;110(1 Pt 1):143-51.

47. Abman SH, Kinsella JP. Inhaled nitric oxide therapy of pulmonary hypertension and respiratory failure in premature and term neonates. Adv Pharmacol. 1995;34:457-74.

48. Kotecha S, Allen J. Oxygen therapy for infants with chronic lung disease. Arch Dis Child Fetal Neonatal Ed. 2002;87(1):F11-4.

49. Supplemental Therapeutic Oxygen for Prethreshold Retinopathy Of Prematurity (STOP-ROP), a randomized, controlled trial. I: primary outcomes. Pediatrics. 2000;105(2):295-310.

50. Group BIUKC, Group BIAC, Group BINZC, Stenson BJ, Tarnow-Mordi WO, Darlow BA, et al. Oxygen saturation and outcomes in preterm infants. N Engl J Med. 2013;368(22):2094-104.

51. American Thoracic S, European Respiratory S. ATS/ERS statement: raised volume forced expirations in infants: guidelines for current practice. Am J Respir Crit Care Med. 2005;172(11):1463-71.

52. Stocks J, Sly PD, Tepper RS, Morgan WJ, editors. Infant Respiratory Function Testing. New York: Wiley-Liss, John Wiley \& Sons, Inc.; 1996.

53. Panitch HB, Allen JL, Alpert BE, Schidlow DV. Effects of CPAP on lung mechanics in infants with acquired tracheobronchomalacia. Am J Respir Crit Care Med. 1994;150(5 Pt 1):1341-6.

54. Zinman R. Tracheal stenting improves airway mechanics in infants with tracheobronchomalacia. Pediatr Pulmonol. 1995;19(5):275-81.

55. Panitch HB, Keklikian EN, Motley RA, Wolfson MR, Schidlow DV. Effect of altering smooth muscle tone on maximal expiratory flows in patients with tracheomalacia. Pediatr Pulmonol. 1990;9(3):170-6. 
56. Shaffer TH, Alapati D, Greenspan JS, Wolfson MR. Neonatal non-invasive respiratory support: physiological implications. Pediatr Pulmonol. 2012;47(9):837-47.

57. Make BJ, Hill NS, Goldberg AI, Bach JR, Criner GJ, Dunne PE, et al. Mechanical ventilation beyond the intensive care unit. Report of a consensus conference of the American College of Chest Physicians. Chest. 1998;113(5 Suppl):289S-344S.

58. Panitch HB, Downes JJ, Kennedy JS, Kolb SM, Parra MM, Peacock J, et al. Guidelines for home care of children with chronic respiratory insufficiency. Pediatr Pulmonol. 1996;21(1):52-6.

59. Allen J, Zwerdling R, Ehrenkranz R, Gaultier C, Geggel R, Greenough A, et al. Statement on the care of the child with chronic lung disease of infancy and childhood. Am J Respir Crit Care Med. 2003;168(3):356-96.

60. Khemani E, McElhinney DB, Rhein L, Andrade O, Lacro RV, Thomas KC, et al. Pulmonary artery hypertension in formerly premature infants with bronchopulmonary dysplasia: clinical features and outcomes in the surfactant era. Pediatrics. 2007;120(6):1260-9.

61. Mourani PM, Sontag MK, Ivy DD, Abman SH. Effects of long-term sildenafil treatment for pulmonary hypertension in infants with chronic lung disease. J Pediatr. 2009;154(3):379-84, 84 e1-2.

62. Schmidt B, Roberts R, Millar D, Kirpalani H. Evidence-based neonatal drug therapy for prevention of bronchopulmonary dysplasia in very-low-birth-weight infants. Neonatology. 2008;93(4):284-7.

63. Schmidt B, Roberts RS, Davis P, Doyle LW, Barrington KJ, Ohlsson A, et al. Caffeine therapy for apnea of prematurity. N Engl J Med. 2006;354(20):2112-21.

64. Gower WA, Wert SE, Nogee LM. Inherited surfactant disorders. NeoReviews. 2008;9:e458-e67.

65. Pavlovic J, Papagaroufalis C, Xanthou M, Liu W, Fan R, Thomas NJ, et al. Genetic variants of surfactant proteins A, B, C, and D in bronchopulmonary dysplasia. Dis Markers. 2006;22(5-6):277-91.

66. Abman SH, Mourani PM, Sontag M. Bronchopulmonary dysplasia: a genetic disease. Pediatrics. 2008;122(3):658-9.

67. Bhandari V, Gruen JR. The genomics of bronchopulmonary dysplasia. NeoReviews. 2007;8:e336-e44.

68. Jobe AH. Effects of chorioamnionitis on the fetal lung. Clin Perinatol. 2012;39(3):441-57.

69. Jobe AH. Mechanisms of Lung Injury and Bronchopulmonary Dysplasia. Am J Perinatol. 2016;33(11):1076-8.

70. Kallapur SG, Kramer BW, Jobe AH. Ureaplasma and BPD. Semin Perinatol. 2013;37(2):94-101.

71. Thebaud B, Goss KN, Laughon M, Whitsett JA, Abman SH, Steinhorn RH, et al. Bronchopulmonary dysplasia. Nat Rev Dis Primers. 2019;5(1):78.

72. Doyle LW, Cheong JL, Ehrenkranz RA, Halliday HL. Late (> 7 days) systemic postnatal corticosteroids for prevention of bronchopulmonary dysplasia in preterm infants. Cochrane Database Syst Rev. 2017;10:CD001145.

73. Doyle LW, Cheong JL, Ehrenkranz RA, Halliday HL. Early ( $<8$ days) systemic postnatal corticosteroids for prevention of bronchopulmonary dysplasia in preterm infants. Cochrane Database Syst Rev. 2017;10:CD001146.

74. Jobe AH. Postnatal corticosteroids for bronchopulmonary dysplasia. Clin Perinatol. 2009;36(1):177-88.

75. Hwang SS, Burris HH, Collins JW, Jr., Kirpalani H, Wright CJ. Moving beyond race and ethnicity to understand the effect of inhaled nitric oxide on bronchopulmonary dysplasia prevention. J Pediatr. 2018;201:298-300. 
76. Kadmon G, Schiller O, Dagan T, Bruckheimer E, Birk E, Schonfeld T. Pulmonary hypertension specific treatment in infants with bronchopulmonary dysplasia. Pediatr Pulmonol. 2017;52(1):77-83.

77. Guaman MC, Gien J, Baker CD, Zhang H, Austin ED, Collaco JM. Point Prevalence, Clinical Characteristics, and Treatment Variation for Infants with Severe Bronchopulmonary Dysplasia. Am J Perinatol. 2015;32(10):960-7.

78. Abman SH, Nelin LD. Management of the infant with severe bronchopulmonary dysplasia. In: Bancalari E, editor. The Newborn Lung: Neonatology Questions and Controversies. Philadelphia (PA): Elsevier Saunders; 2012. p. 407-25.

79. Napolitano N, Jalal K, McDonough JM, Monk HM, Zhang H, Jensen E, et al. Identifying and treating intrinsic PEEP in infants with severe bronchopulmonary dysplasia. Pediatr Pulmonol. 2019;54(7):1045-51.

80. Eichenwald C, Dysart K, Zhang H, Fox W. Neonatal Partial Liquid Ventilation for the Treatment and Prevention of Bronchopulmonary Dysplasia. Neoreviews. 2020;21(4):e238-e48.

81. Jobe AH, Steinhorn R. Can We Define Bronchopulmonary Dysplasia? J Pediatr. 2017;188:19-23.

82. Tooley WH. Epidemiology of bronchopulmonary dysplasia. J Pediatr. 1979;95(5 Pt 2):851-8.

83. Bancalari E, Abdenour GE, Feller R, Gannon J. Bronchopulmonary dysplasia: clinical presentation. J Pediatr. 1979;95(5 Pt 2):819-23.

84. Shennan AT, Dunn MS, Ohlsson A, Lennox K, Hoskins EM. Abnormal pulmonary outcomes in premature infants: prediction from oxygen requirement in the neonatal period. Pediatrics. 1988;82(4):527-32.

85. Abman SH, Collaco JM, Shepherd EG, Keszler M, Cuevas-Guaman M, Welty SE, et al. Interdisciplinary Care of Children with Severe Bronchopulmonary Dysplasia. J Pediatr. 2017;181:12-28 e1.

86. Stoll BJ, Hansen NI, Bell EF, Walsh MC, Carlo WA, Shankaran S, et al. Trends in Care Practices, Morbidity, and Mortality of Extremely Preterm Neonates, 1993-2012. JAMA. 2015;314(10):1039-51.

87. Allen JL. Airway function throughout the lifespan: Pediatric origins of adult respiratory disease. Pediatr Investig. 2019;3(4):236-44.

88. Bui DS, Burgess JA, Lowe AJ, Perret JL, Lodge CJ, Bui M, et al. Childhood Lung Function Predicts Adult Chronic Obstructive Pulmonary Disease and Asthma-Chronic Obstructive Pulmonary Disease Overlap Syndrome. Am J Respir Crit Care Med. 2017;196(1):39-46.

89. McGrath-Morrow SA, Collaco JM. Bronchopulmonary dysplasia: what are its links to COPD? Ther Adv Respir Dis. 2019;13:1753466619892492. 


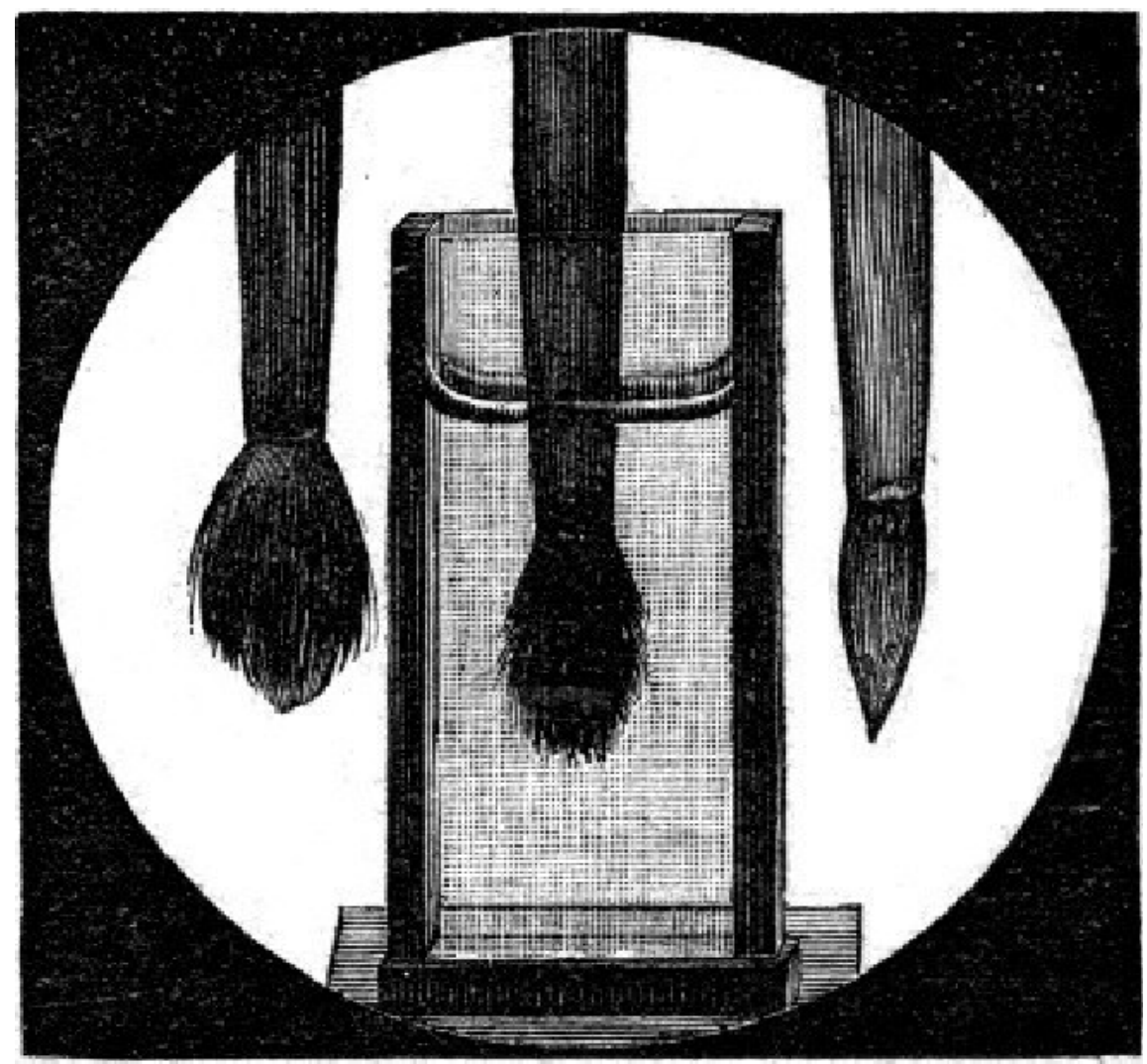




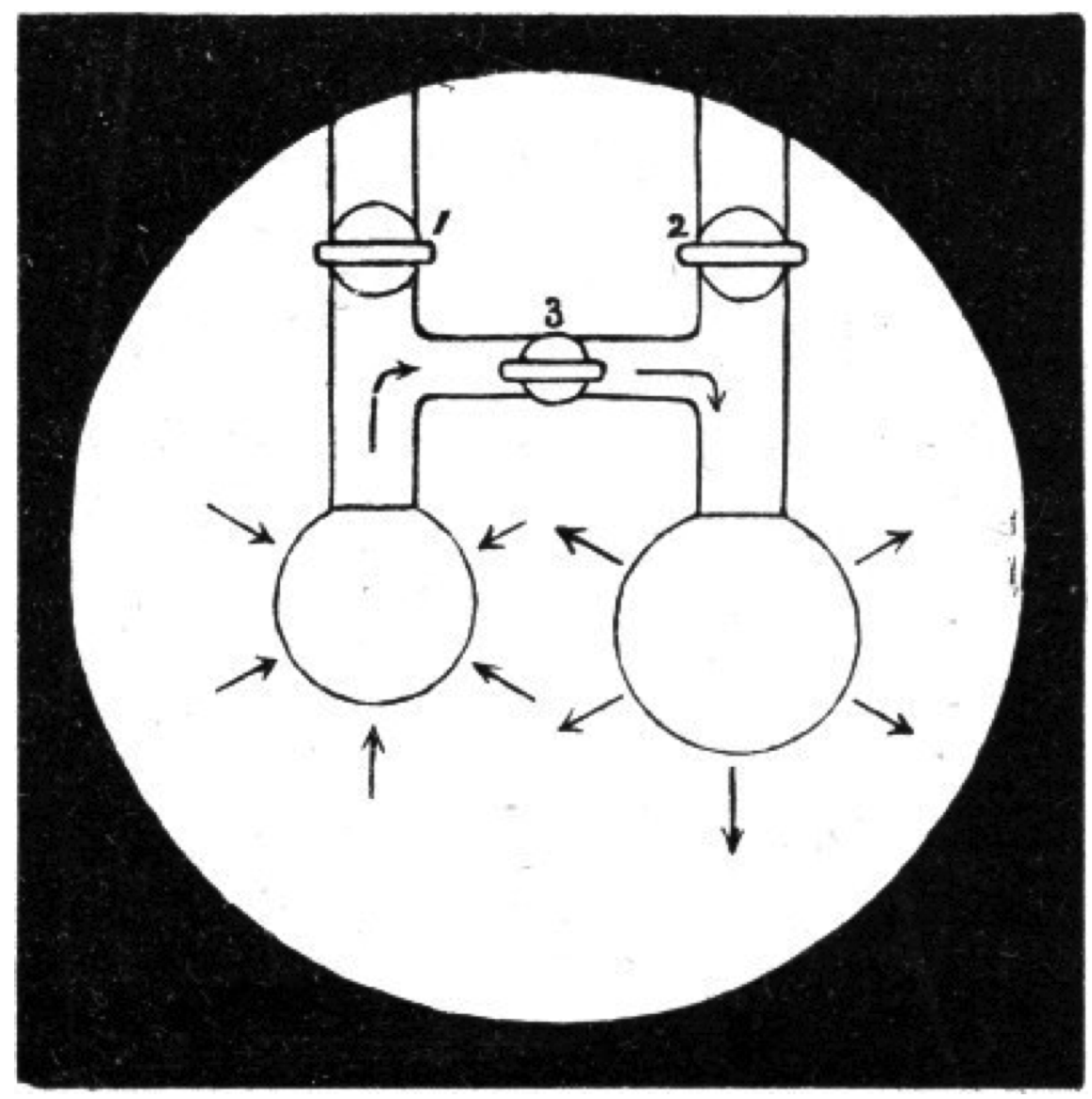




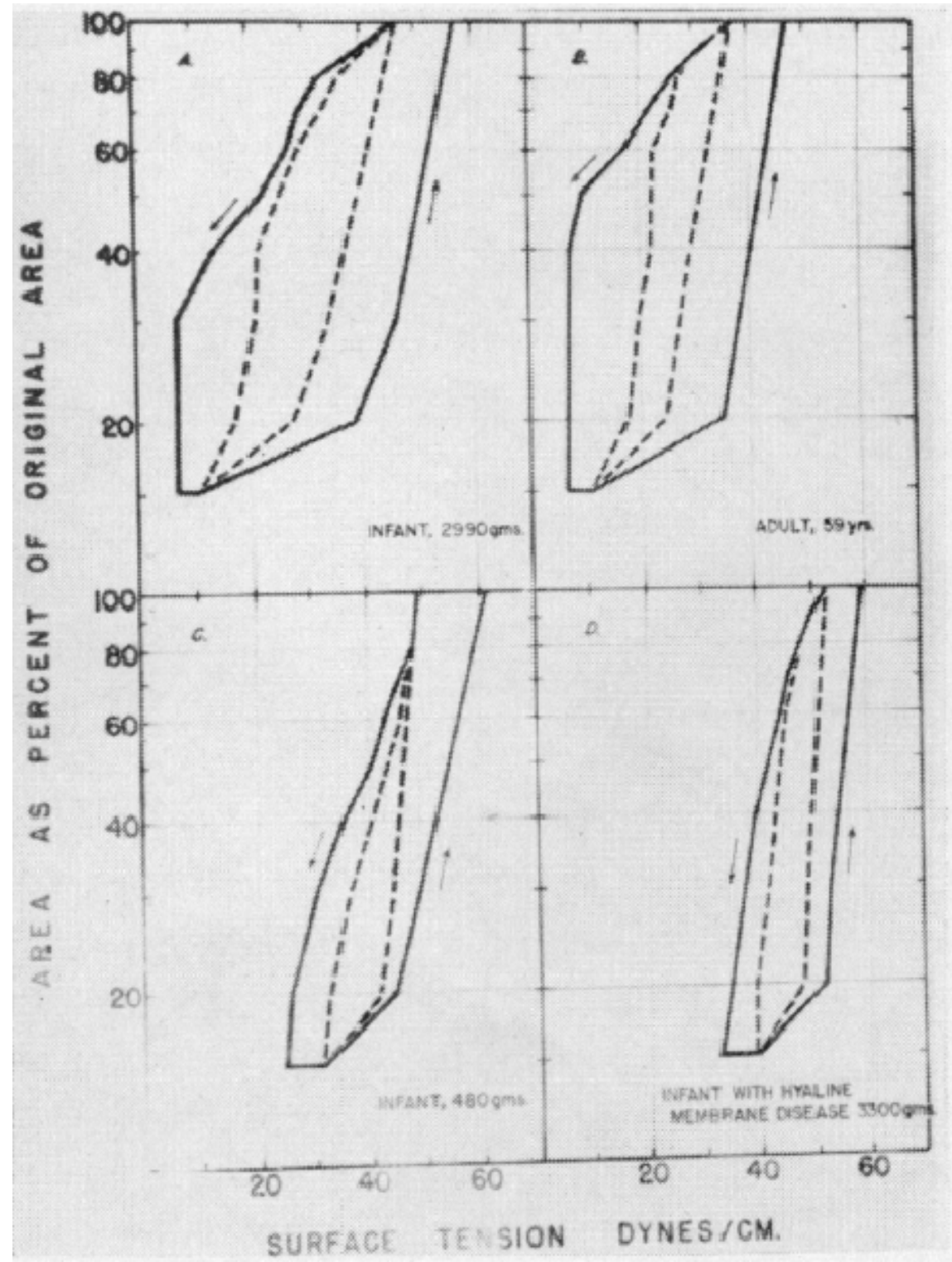



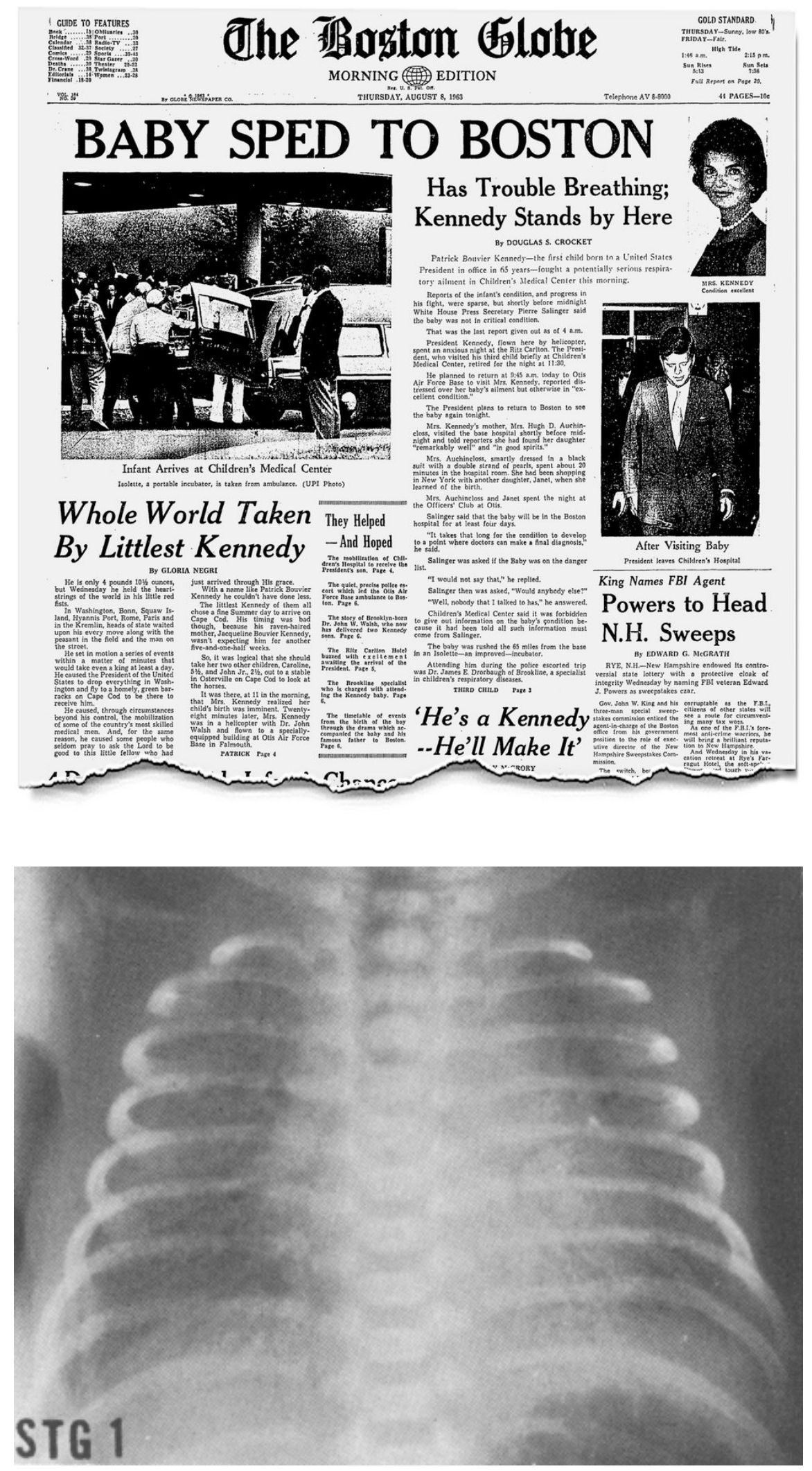


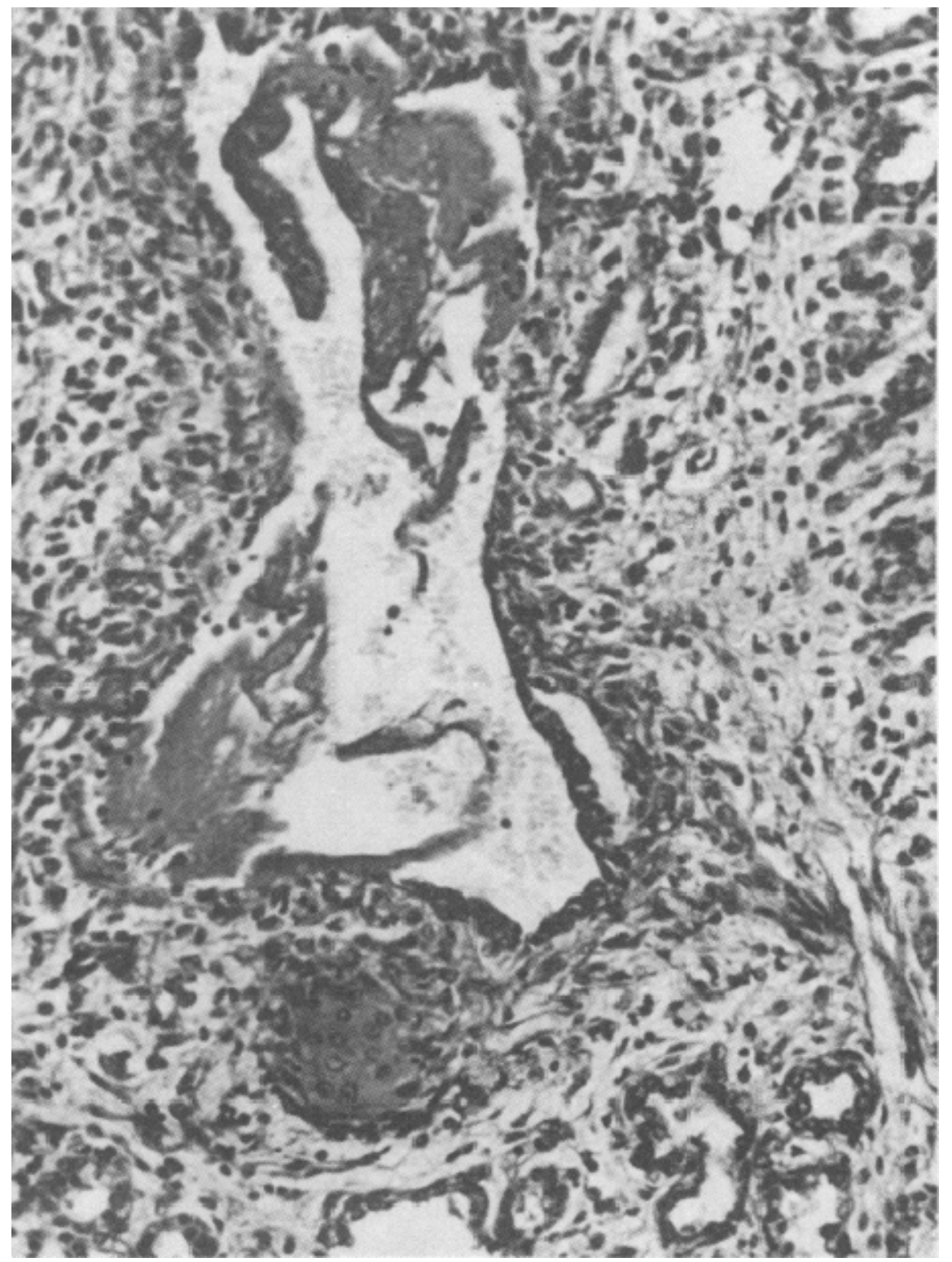




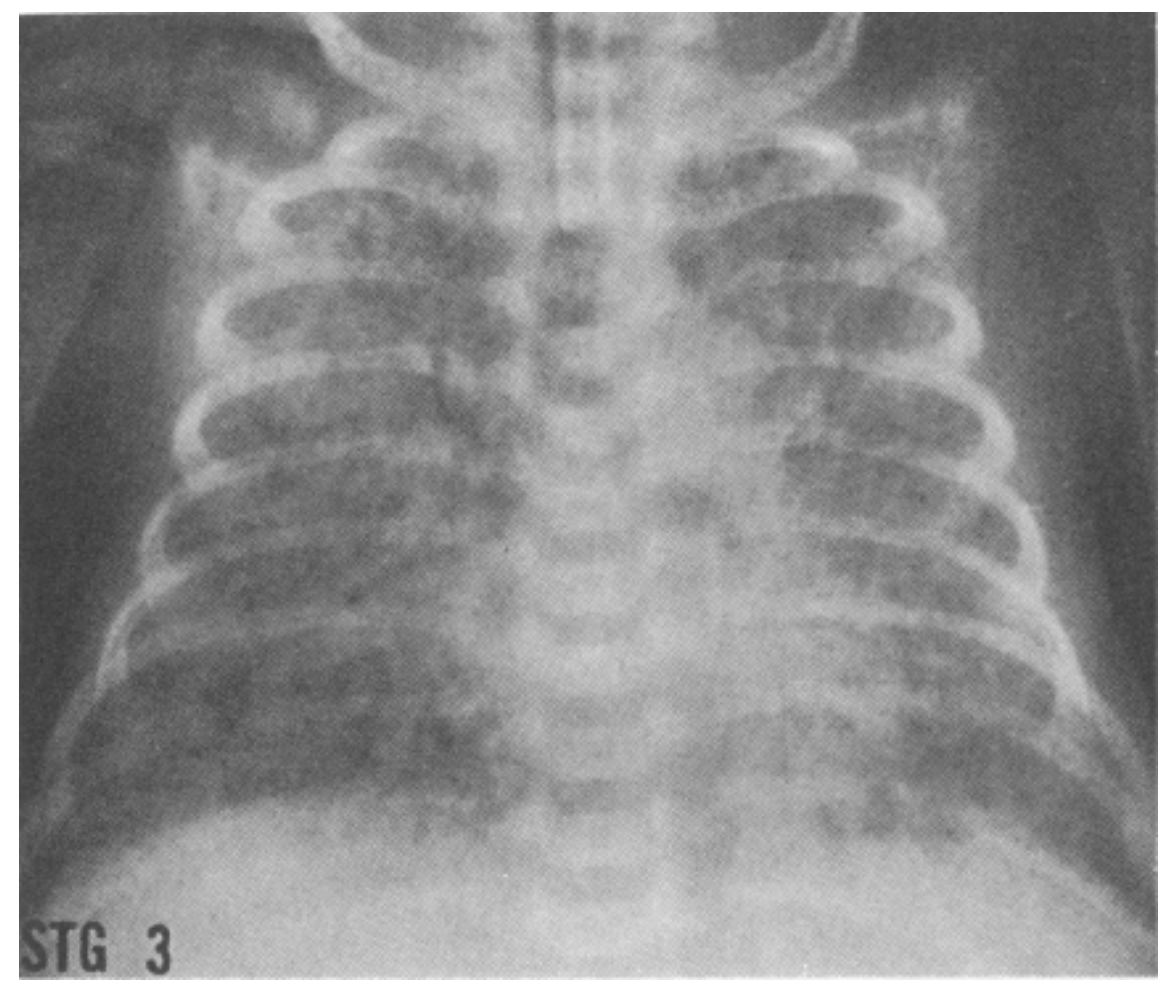




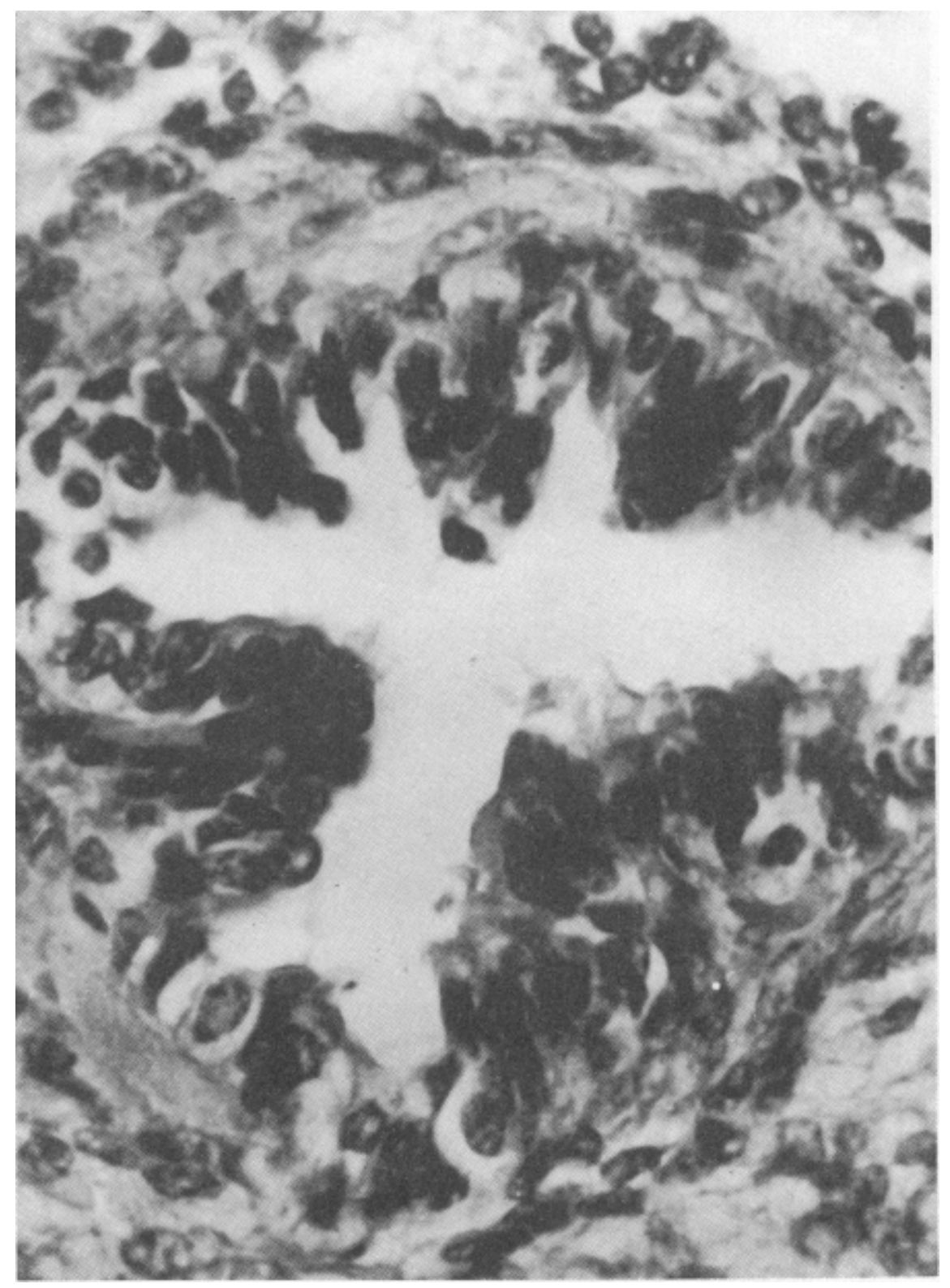



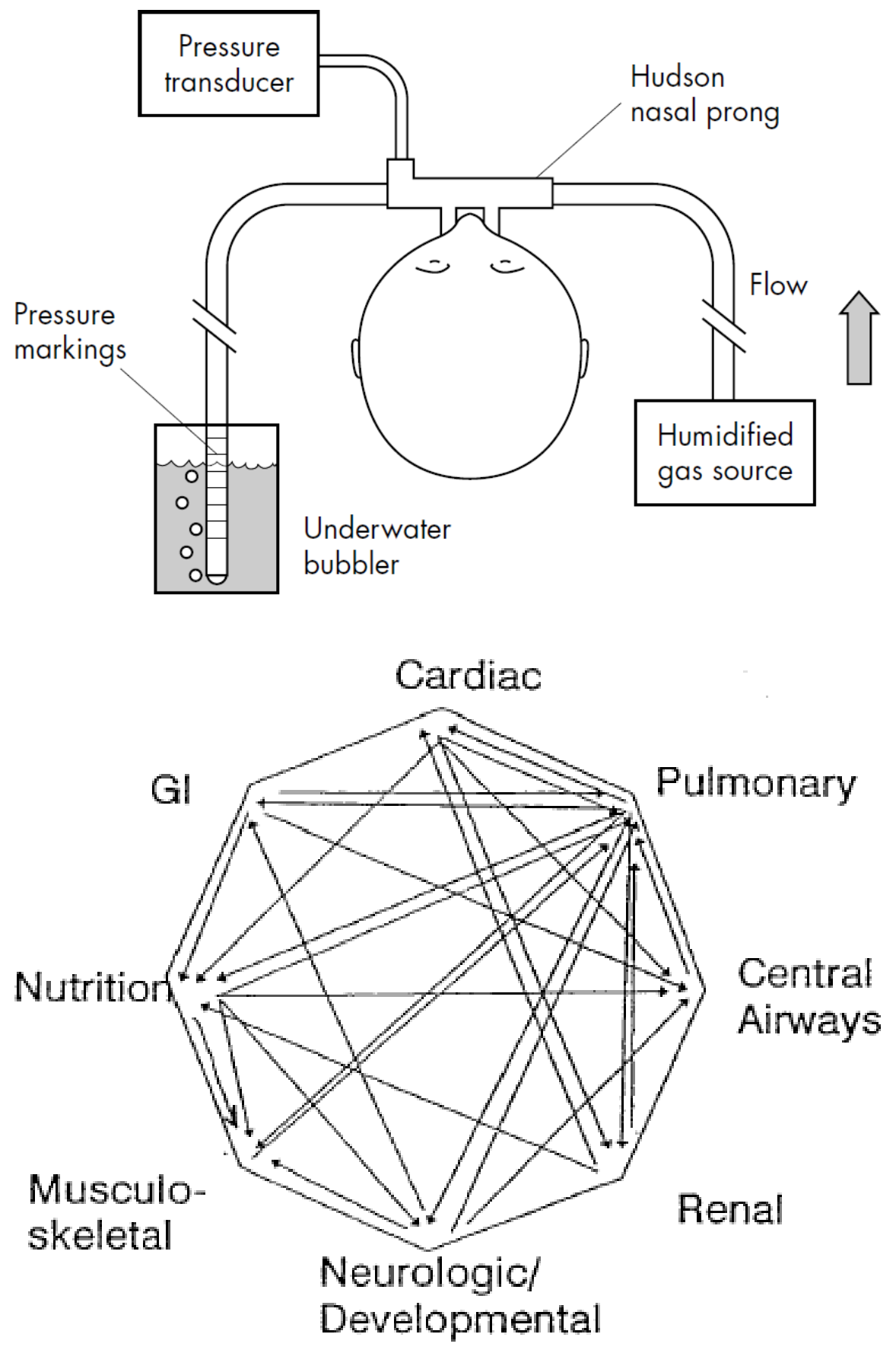